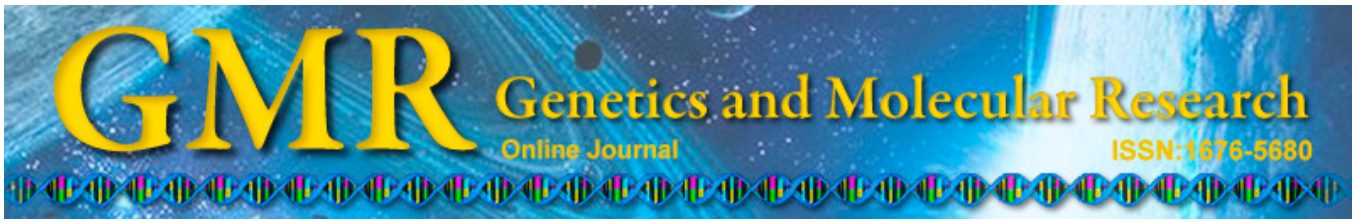

\title{
Proacrosin activation mechanisms in capacitated and frozen-thawed boar spermatozoa
}

\author{
J.J. Cui, Y. Tian, Y. Liu, H.L. Huang and Y. Jin \\ Agricultural College of Yanbian University, Yanji, Jinlin, China \\ Corresponding author: Y. Jin \\ E-mail: yijin@ybu.edu.cn
}

Genet. Mol. Res. 13 (4): 9915-9920 (2014)

Received January 6, 2014

Accepted March 20, 2014

Published November 27, 2014

DOI http://dx.doi.org/10.4238/2014.November.27.20

\begin{abstract}
The main objective of the current study was to explore the different activation mechanisms of capacitation and freezethawed spermatozoa. Using SDS-PAGE and Western blotting, the conversion process of boar proacrosin during freeze-thawing and capacitation of spermatozoa was analyzed. The results revealed that capacitated spermatozoa exhibited a greater fluorescence area than that of the freeze-thawed spermatozoa, which were smaller than those of the fresh group. Fresh spermatozoa displayed 45- and 35$\mathrm{kDa}$ protein bands, while those of freeze-thawed andcapacitated spermatozoa displayed 45-, 35- and 28-kDa bands. In summary, these data indicate that proacrosin is activated, thus becoming $\alpha$ and $\beta$-acrosins and a $28-\mathrm{kDa}$ protein during capacitation and freezethawing.
\end{abstract}

Key words: Boar sperm; Proacrosin; Freeze-thaw; Capacitation; SDS-PAGE; Western blotting 


\section{INTRODUCTION}

Low fertilization rates of freeze-thawed spermatozoa are thought to be caused by damage to the spermatozoa (Bailey et al., 2000), including capacitation-like changes, which have been referred to as cryocapacitation (NagDas, 1992). Reports have shown that the sperm acrosome contains as many as 24 enzymes, including proteases and phospholipases; among them, acrosin is the most relevant to fertilization (Barros et al., 1996). Studies have provided evidence that acrosin primarily exists (85-90\%) as proacrosin in ejaculated semen (Cormier and Bailey, $2003)$. The boar proacrosin ( 55 and $53 \mathrm{kDa}$ ) is automatically activated to become $\alpha$-acrosin (45-49 kDa), which is then transformed into mature $\beta$-acrosin (34-38 kDa) (Moos et al., 1993a). Acrosin is capable of recognizing and penetrating the zona pellucida. However, damaged spermatozoa experience decreased fertilization capabilities (Barros et al., 1996). Therefore, the objective of the current study was to explore the transformation mechanism of proacrosin during the freeze-thawing process to clarify the underlying mechanisms affecting capacitation-like and capacitation spermatozoa. This study could provide a theoretic basis for improving technologies for freeze-thawing semen

\section{MATERIAL AND METHODS}

\section{Boar semen}

Semen was provided by the Hanji Husbandry and was collected from 8 Duroc boars using a manual semen collection method.

\section{Reagents}

All reagents were purchased from Sigma (Beingjing, China), except where indicated otherwise. Anti-acrosin (ACR-2) and HRP-goat-anti-mouse IgG $\mathrm{h}+1$ were purchased from Shanghai Youning Biotech. The prestained protein marker, NC membrane, DAB color development solution, and other immunoblotting reagents were obtained from Beijing Colourful Biotechnology.

\section{Frozen solution preparation}

The frozen solution was made by mixing the following: $2420 \mathrm{mg}$ Tris, $1480 \mathrm{mg}$ citrate, and $1100 \mathrm{mg}$ glucose in $100 \mathrm{~mL}$ triple distilled water. Frozen dilution solution A was made by freshly adding $20 \%(\mathrm{v} / \mathrm{v})$ egg yolk to the base frozen solution. Frozen dilution solution B was made by freshly mixing $9 \%(\mathrm{v} / \mathrm{v})$ glycerol into frozen dilution solution A.

\section{Capacitation solution}

The capacitation solution $(100 \mathrm{~mL})$ contained $661 \mathrm{mg} \mathrm{NaCl}, 22.3 \mathrm{mg} \mathrm{KCl}, 110.2 \mathrm{mg}$ $\mathrm{CaCl}_{2}, 55 \mathrm{mg}$ sodium pyruvate, and $200 \mathrm{mg}$ caffeine. The solution was filtered through a $0.22-\mu \mathrm{m}$ filter and stored at $-4^{\circ} \mathrm{C}$.

\section{Antibody dilution}

The antibody dilution solution was prepared by mixing $500 \mu \mathrm{L}$ Tween 20 with 1000 
$\mathrm{mL}$ PBS and then filtered. The primary antibody was diluted by mixing with a dilution solution at 1:50 for fluorescent staining; it was further diluted (1:4) for Western blotting and stored at $4^{\circ} \mathrm{C}$ in the dark. Secondary antibody (HRP-goat-anti-mouse IgG $\mathrm{h}+1$ ) was prepared by diluting to $1: 5000$ and maintained in the dark.

\section{Freezing and thawing}

For the freezing process, racks were set $3 \mathrm{~cm}$ above the surface of liquid nitrogen for $10 \mathrm{~min}$; then, small tubes were set horizontally on the rack, covered with a lid (allowed to steam for $10 \mathrm{~min}$ ), and then rapidly set into liquid nitrogen.

For the thawing process, tubes were removed from liquid nitrogen and immediately put into a water bath at $37^{\circ} \mathrm{C}$ for $60 \mathrm{~s}$. After thawing, the tubes were blotted dry and cut from the sealed end.

\section{Spermatozoa capacitation}

The washing solution mPBS and capacitation solution were warmed by setting at room temperature for $20 \mathrm{~min}$. Semen samples were diluted (1:1) in $\mathrm{mPBS}$ and centrifuged for $5 \mathrm{~min}$ at $500 \mathrm{rpm}$. The pellet was suspended in $2 \mathrm{~mL}$ capacitation solution containing $20 \mu \mathrm{g} / \mathrm{mL}$ heparin and incubated for $2 \mathrm{~h}$ in a $5 \% \mathrm{CO}_{2}$ incubator at $39^{\circ} \mathrm{C}$ and a $45^{\circ}$ angle. The swim-up method was used.

\section{Protein extraction}

Pretreated semen was spun at $150 \mathrm{rpm}$ for $10 \mathrm{~min}$ at $4^{\circ} \mathrm{C}$. A volume of $6 \mathrm{~mL}$ sperm supernatant was washed with filtered water and then spun at $150 \mathrm{rpm}$ for $10 \mathrm{~min}$ to remove spermatogonia. A volume of $6 \mathrm{~mL}$ supernatant was spun again at $3000 \mathrm{rpm}$ for $10 \mathrm{~min}$; the pellet was resuspended in $3 \mathrm{~mL}$ cold PBS $(0.1 \mathrm{~mL} / \mathrm{L}, \mathrm{pH} 7.4,0.7 \% \mathrm{NaCl})$, combined, and spun at $3000 \mathrm{rpm}$ for $10 \mathrm{~min}$ at $4^{\circ} \mathrm{C}$. The pellet was again washed with $6 \mathrm{~mL}$ cold PBS, and the supernatant was removed with centrifugation at $3000 \mathrm{rpm}$ for $10 \mathrm{~min}$. The preparation was washed twice with Tris-HCl buffer ( $0.1 \mathrm{M}, \mathrm{pH} 7.4,0.7 \% \mathrm{NaCl}, 1 \mathrm{mM}$ EDTA, $0.5 \mathrm{mM}$ PMSF). Finally, spermatozoa were suspended in $1 \mathrm{~mL}$ Tris- $\mathrm{HCl}$ buffer. The membrane protein was extracted by mixing with an extraction buffer containing $1 \%$ Triton X-100 and shaking for $1.5 \mathrm{~h}$ in a water bath. The membrane proteins were collected with the supernatant after centrifugation at $5000 \mathrm{rpm}$ for $15 \mathrm{~min}$.

\section{Statistical analysis}

Data were analyzed with SPSS 11.5. $\mathrm{P}<0.05$ was considered to be statistically significant.

\section{RESULTS AND DISCUSSION}

\section{Indirect fluorescent staining of proacrosin incapacitation and capacitation-like spermatozoa}

Figure 1 shows the fluorescence that was observed in the spermatozoa from 3 treatment groups. Spermatozoa in the capacitation group exhibited a larger area of fluorescence than those in the freeze-thawed group. Spermatozoa in the fresh group exhibited the largest area of fluorescence. These results show that proacrosin in the freeze-thawed group was par- 
tially damaged, and proacrosin was partially activated during capacitation.

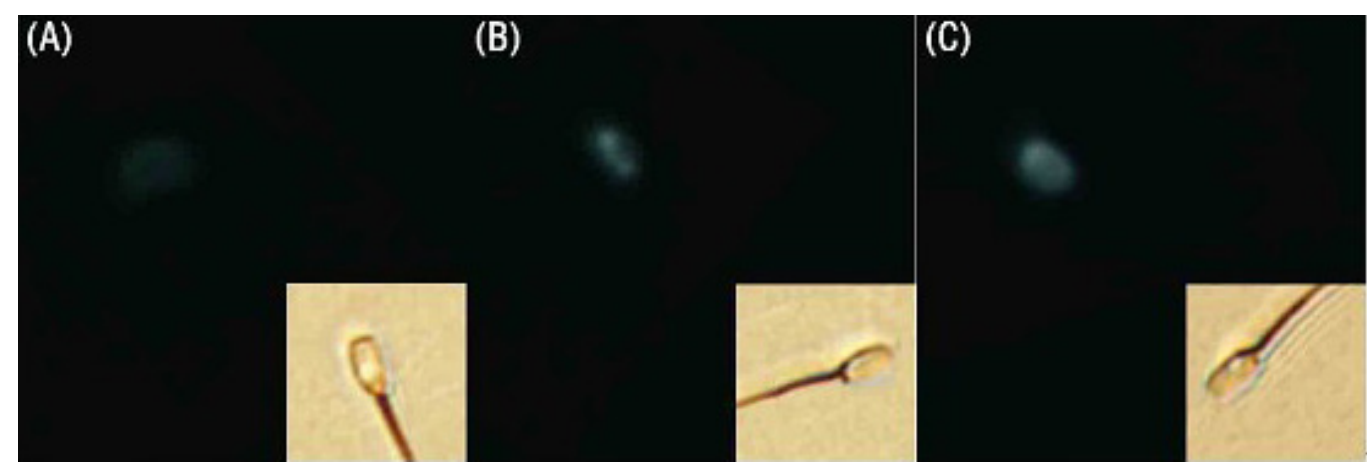

Figure 1. Fluorescent staining of proacrosin. A. Fresh spermatozoon. B. Frozen-thawed spermatozoon. C. Capacitation spermatozoon.

\section{SDS electrophoresis analysis of capacitation and capacitation-like spermatozoa}

SDS-PAGE analysis indicates that proteins in all treatment groups were isolated. The fresh spermatozoan group contained proteins ranging from 55 to $95 \mathrm{kDa}$ (Figure 2). The proteins were distributed evenly in both the capacitation and freeze-thawed groups. New bands were produced and some bands disappeared. These results indicate the occurrence of notable changes in protein species and levels in the treatment group when compared to those in the control groups.

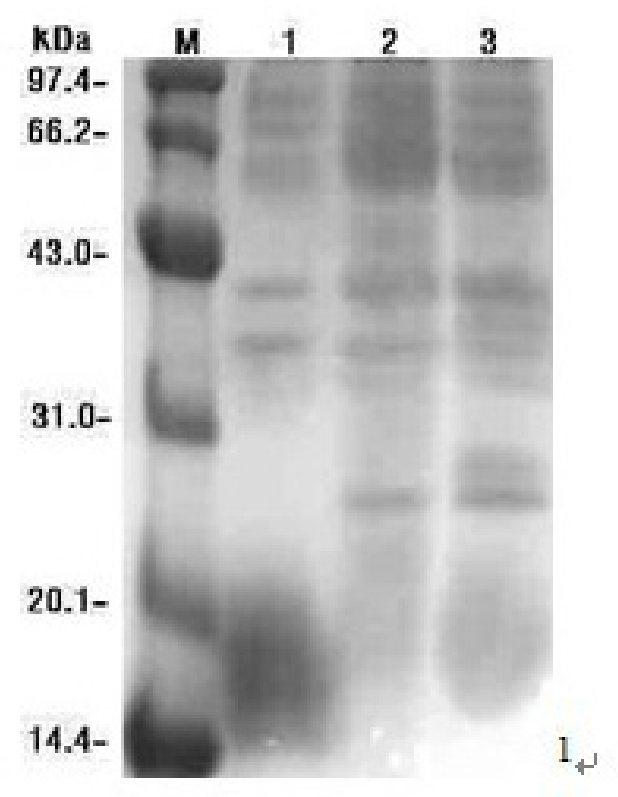

Figure 2. Electrophoresis analysis of proacrosin. Lane $M=$ protein standard; lane $1=$ fresh spermatozoa; lane $2=$ frozen-thawed spermatozoa; lane 3 = capacitation spermatozoa. 


\section{Western blot analysis of capacitation and capacitation-like spermatozoa}

Samples of fresh, freeze-thawed, and capacitation spermatozoa were separated using SDS-PAGE, and then analyzed using Western blot analysis. Figure 3 shows that fresh spermatozoa exhibited 45- and 35-kDa bands, but the freeze-thawed and capacitation spermatozoa exhibited 45-, 35-, and $28-\mathrm{kDa}$ bands. This result indicates that proacrosin was partially activated to $\alpha$-acrosin and $\beta$-acrosin and a $28-\mathrm{kDa}$ protein.

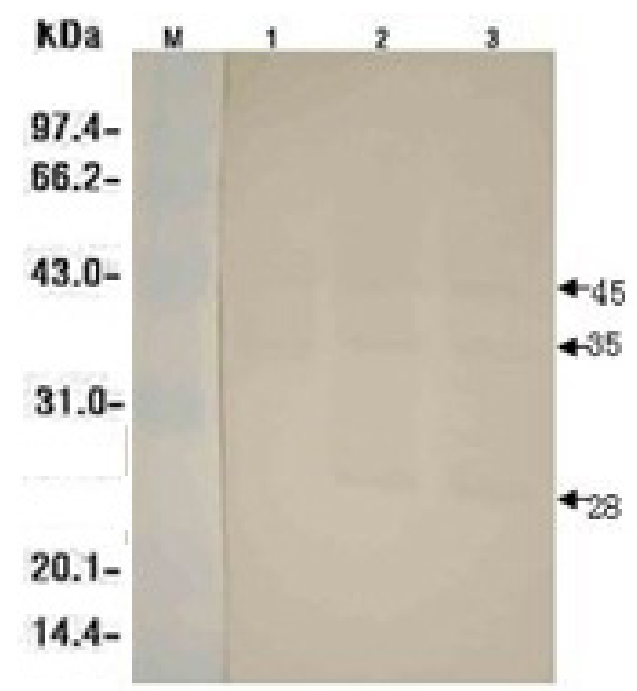

Figure 3. Westem blot analysis of proacrosin. Lane $M=$ protein standard; lane $1=$ fresh spermatozoa; lane $2=$ frozen-thawed spermatozoa; lane 3 = capacitation spermatozoa.

\section{DISCUSSION AND CONCLUSION}

The capacitation-like and capacitation spermatozoa exhibited a high degree of similarity; however, significant differences were found in the acrosin levels between the diluted semen and freeze-thawed semen when analyzed according to the method described by Kennedy et al. (1989). The level of acrosin is positively correlated with in vitro fertilization rates (Kennedy et al., 1989). The authors analyzed fresh, capacitation and freeze-thawed boar spermatozoa via SDS-PAGE and Western blotting and displayed them with anti-acrosin monoclonal and enzyme-linked antibodies. The results showed that the fresh spermatozoa were expressed at 45 and $35 \mathrm{kDa}$. In addition, the freeze-thawed and capacitation spermatozoa expressed $45-, 35-$ and $28-\mathrm{kDa}$ proteins. These results indicate that proacrosin was partially activated to $\alpha$-acrosin and $\beta$-acrosin in the freeze-thawed and capacitation spermatozoa.

A $28-\mathrm{kDa}$ protein was observed in the freeze-thawed and capacitation spermatozoa. Hardy et al. (1991) first showed the existence of a $28-\mathrm{kDa}$ protein in guinea pig spermatozoa. This protein is widely hydrolyzed by acrosin, and the process is closely associated with the disappearance of the acrosomal matrix. Studies have shown that the $28-\mathrm{kDa}$ protein binds with proacrosin and $49-\mathrm{kDa} \alpha$-acrosin, but not with the $36-\mathrm{kDa} \beta$-acrosin, thus maintaining the integrity of the acrosomal matrix and controlling acrosin release in the acrosomal reaction (Moos et al., 1993b). However, this mechanism requires further study. 


\section{ACKNOWLEDGMENTS}

Research supported by the National Natural Science Foundation of China (\#31260529) and the Natural Science Foundation of Jilin Province (\#201115229).

\section{REFERENCES}

Bailey JL, Bilodeau JF and Cormier N (2000). Semen cryopreservation in domestic animals: a damaging and capacitating phenomenon. J. Androl. 21: 1-7.

Barros C, Crosby JA and Moreno RD (1996). Early steps of sperm-egg interactions during mammalian fertilization. Cell Biol. Int. 20: 33-39.

Cormier N and Bailey JL (2003). A differential mechanism is involved during heparin- and cryopreservation-induced capacitation of bovine spermatozoa. Biol. Reprod. 69: 177-185.

Hardy DM, Oda MN, Friend DS, Huang TT Jr (1991). A mechanism for differential release of acrosomal enzymes during the acrosome reaction. Biochem J. 275: 759-766.

Kennedy WP, Kaminski JM, Van der Ven HH, Jayendran RS, et al. (1989). A simple, clinical assay to evaluate the acrosin activity of human spermatozoa. J. Androl. 10: 221-231.

Moos J, Peknicova J and Tesarik J (1993a). Relationship between molecular conversions of acrosin and the progression of exocytosis in the calcium ionophore-induced acrosome reaction. Biochim. Biophys. Acta 1176:199-207.

Moos J, Peknicova J and Tesarik J (1993b). Protein-protein interactions controlling acrosin release and solubilization during the boar sperm acrosome reaction. Biol. Reprod. 49: 408-415.

NagDas SK (1992). Bovine epididymal sperm proacrosin-acrosin system: quantification and partial characterization. Andrologia 24: 171-178. 